\title{
Study on the treatment of oily wastewater by natural organic polymer modified flocculan
}

\author{
Lin Zhu ${ }^{1 *}$ \\ ${ }^{1}$ Biological Engineering Department, Liaoning Economic Management Cadre Institute, Shenyang, \\ 110122, P. R. China \\ * Corresponding author: Biological Engineering Department, Liaoning Economic Management \\ Cadre Institute, Shenyang, 110122, P. R. China. Tel: 86-24-89873812. E-mail address: \\ zhulinapple@163.com
}

Keywords: Organic flocculant, starch modified flocculant ( FSM ) ,polysilicate aluminum sulfate(PSAS), Flocculation performance, oily wastewater, water treatment;

Abstract. In this paper, the preparation methods of flocculants are analyzed and summarized. Organic and inorganic polymeric flocculants. Their flocculation properties were studied, and the synthesis of green organic flocculant and its flocculation performance were carried out. Finally, this kind of research is combined with inorganic flocculant to carry out the experimental exploration of oily wastewater. The experimental material uses natural organic polymer material, corn starch, because it is rich in origin and low in price. By using ceric ammonium nitrate as initiator, graft monomer with acrylamide, through graft copolymerization, grafting with starch macromolecule acrylamide, made of green natural organic polymer flocculant. The application of this method to oily wastewater treatment was also studied.

\section{Introduction}

The development of China's economy has stimulated the development of automobiles, transportation and other oil industries. The increase in oil demand has accelerated the rapid development of oil refining and refining industries. According to the survey, there are seven water treatment stations in an oil production plant in northern China, and the sewage treatment needs to be as high as $13 \mathrm{~m}^{3} / \mathrm{d}$. Because of cost and other reasons, four of them did not stand on the oily wastewater treatment of reinjection water treatment agent, and various other three stations consumed in 2000, only a flocculant of 333 tons, the treatment cost is 1 million 10 thousand Yuan ${ }^{[1]} .2001 \sim 2003$ emissions of oily wastewater were $2.685 \times 10^{7}$ tons, $2.696 \times 10^{7}$ tons and $3.959 \times 10^{7}$ tons, This phenomenon not only caused serious waste of resources, but also caused serious water pollution. The reason is that the effluent CODcr is seriously out of standard, the standard rate is less than $50 \%$, especially the heavy oil wastewater and polymer wastewater treatment rate is lower than ${ }^{[2]}$. Therefore, oily wastewater treatment is not only an important part of saving and making full use of oil resources, but also an important issue to prevent environmental pollution.

Bioflocculant has unique structure and function ${ }^{[3]}$.It has the characteristics of easy degradation, little pollution to environment and high efficiency. It is likely to become an upgraded product of the existing chemical flocculant ${ }^{[4-5]}$.In oil separation, removal and other areas of development and application prospects are very broad ${ }^{[6,7]}$. There are many research projects in this field. Natural organic polymer modified flocculants are rich in raw materials, low in price, safe and non-toxic. They can be completely degraded and have good "environmental acceptability". Therefore, in organic flocculant research, the development of this aspect gradually attracted people's attention. Moreover, the extraction and improvement of flocculants from agricultural and sideline products is of great significance to the developing countries. For example, China will make full use of natural resources and take the road of sustainable development. 


\section{Experiment scheme and design idea}

This article uses corn starch as raw material because of its wide range and low price. Acrylamide was connected on the molecular chain of corn starch by cerium ion initiated copolymerization. Starch modified flocculant (FSM) was prepared. On the basis of the experiment, the influence of the following conditions on the graft reaction was investigated through the determination of the grafting rate. Conditions include initiator concentration, amount of acrylamide, monomer dosing method and monomer dosing sequence. The process of graft copolymerization was optimized from the experimental conditions. Flocculation performance was investigated by flocculation experiment, and it was combined with polysilicate aluminum sulfate flocculant. Used to treat oily wastewater

\section{Experiment}

1. Synthesis of graft copolymer of acrylamide onto starch

A certain amount of starch and $200 \mathrm{ml}$ water were added to the four bottles. Four bottles to include

Reflux condenser, electric stirrer, nitrogen inlet and outlet and thermometer. 30 Minutes was gelatinized at $85^{\circ} \mathrm{C}$ with nitrogen as protective gas. Then the temperature was reduced to $50^{\circ} \mathrm{C}$ immediately and a certain amount of acrylamide monomer was added. At the same time, a certain concentration of ceric ammonium nitrate initiator solution was added to protect the nitrogen. Stir and react for 3 hours, then cool down to room temperature. Remove the sample and reserve it.

2. Purification of graft chain polyacrylamide

The starch on graft chain can be removed by acid solution ${ }^{[8]}$. The method is to take the graft copolymer $1.0 \mathrm{~g}$ at room temperature, add $5 \mathrm{~mL}$ water and $5 \mathrm{~mL}$ concentrated hydrochloric acid, and heat in the distillation bottle for 2 minutes. Then, the precipitate is precipitated with methanol in ice water, and the purified product is graft chain polyacrylamide, In different literatures, the heating reflux time varied greatly during acid hydrolysis, some reflux for 2 hours, and some reflux for 3 hours ${ }^{[9]}$.If the reflux time is too long, it has an effect on polyacrylamide.

\section{Influence factors of flocculation effect}

1. Effect of dosage of flocculant on flocculation effect

The dosage of flocculant is the key to flocculation, which determines the destabilization of colloid in water, and affects the quantity of flocs after filtration.

2. Effect of water $\mathrm{pH}$ value on flocculation efficiency

The $\mathrm{pH}$ value has great influence on flocculation. It has effects on many conditions, such as the charge on the surface of colloidal particles, the properties and flocculation of flocculants. The $\mathrm{pH}$ value of water body also influences the dosage of flocculant.

3. Effect of temperature on flocculation effect

Generally, the flocculation effect increases with the increase of water temperature. When the water temperature is too low, the reaction of some flocculants slows down, which will affect the amount of water treatment. Therefore, the effect of water temperature on flocculation effect should be studied experimentally.

4. Effect of dosing sequence on flocculation efficiency

Because the mechanism of inorganic flocculant and organic flocculant is different. Therefore, the order of their addition will affect the flocs. For example, the speed of creation and the degree of looseness of the structure.

\section{Results and discussion}

1. Influence factors of graft copolymerization

\section{( 1 ) Effect of initiator concentration on grafting rate}

Taking starch $5 \mathrm{~g}$, acrylamide $10 \mathrm{~g}$, polymerization temperature $50^{\circ} \mathrm{C}$, reaction time 3 hours, changing initiator concentration, the effect of initiator concentration on grafting rate was obtained, as shown in fig. 1 . Therefore, the optimum concentration of initiator is $3 \times 10^{-3} \mathrm{~mol} / \mathrm{L}$. 


\section{( 2 ) Effect of monomer concentration on grafting rate}

when starch: acrylamide is $1: 2$, the grafting rate reaches the maximum value of $184 \%$. Therefore, the best feeding ratio is starch: acrylamide $=1: 2$, that is, the amount of acrylamide is $10 \mathrm{~g}$.
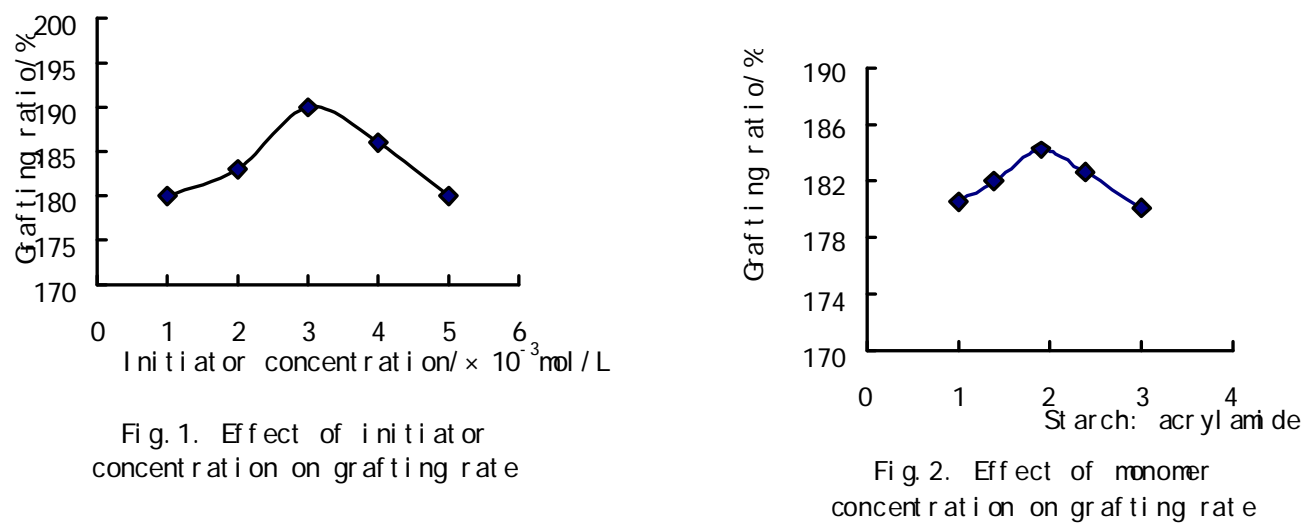

( 3 ) Effect of monomer addition mode on grafting rate

Maintain the original conditions and change the dosing mode of acrylamide. Solid disposable dosing, liquid one-time dosing; solid 10 minutes, 3 times; liquid 10 minutes, 3 times dosing. The best way is to use liquid form and add it several times. The results are shown in Table 1.

Table 1 Effect of monomer addition mode on grafting rate

\begin{tabular}{cc}
\hline Monomer dosing method & Grafting ratio /\% \\
\hline Solid form one-time dosing & 183.2 \\
Liquid form one-time dosing & 189.6 \\
Multiple addition in solid form & 184.5 \\
Multiple dosing in liquid form & 191.4 \\
\hline
\end{tabular}

( 4 ) Effect of monomer addition order on grafting ratio

Keep the condition unchanged .Adding acrylamide in liquid form and changing the adding order of acrylamide monomer affect the effect table 2 . From table 2, the grafting rate of acrylamide was higher than that of initiator and acrylamide when the initiator was added.

Table 2 Effect of monomer addition order on grafting ratio

\begin{tabular}{cc}
\hline Monomer addition order & Grafting ratio /\% \\
\hline First, the initiator and then the monomer & 193.8 \\
acrylamide when the initiator was added. & 191.4 \\
\hline
\end{tabular}

2. Influence factors of flocculation effect of starch modified flocculant

\section{( 1 ) Effect of PSAS dosage on flocculation efficiency}

Keep the temperature of original water sample unchanged in $200 \mathrm{~mL}$ oily wastewater sample, keep the $\mathrm{pH}$ value of original water sample unchanged. The dosage of PSAS was changed, and the effect of PSAS dosage on flocculation efficiency was obtained. As shown in fig. 3. It can be seen from fig. 3.The optimum dosage of PSAS is $3 \mathrm{~mL} / 200 \mathrm{~mL}$ oily wastewater。

\section{( 2 ) Effect of FSM dosage on flocculation efficiency.}

Keep the original conditions unchanged, change the dosage of FSM, get the effect of FSM dosage on flocculation effect fig. 4. 

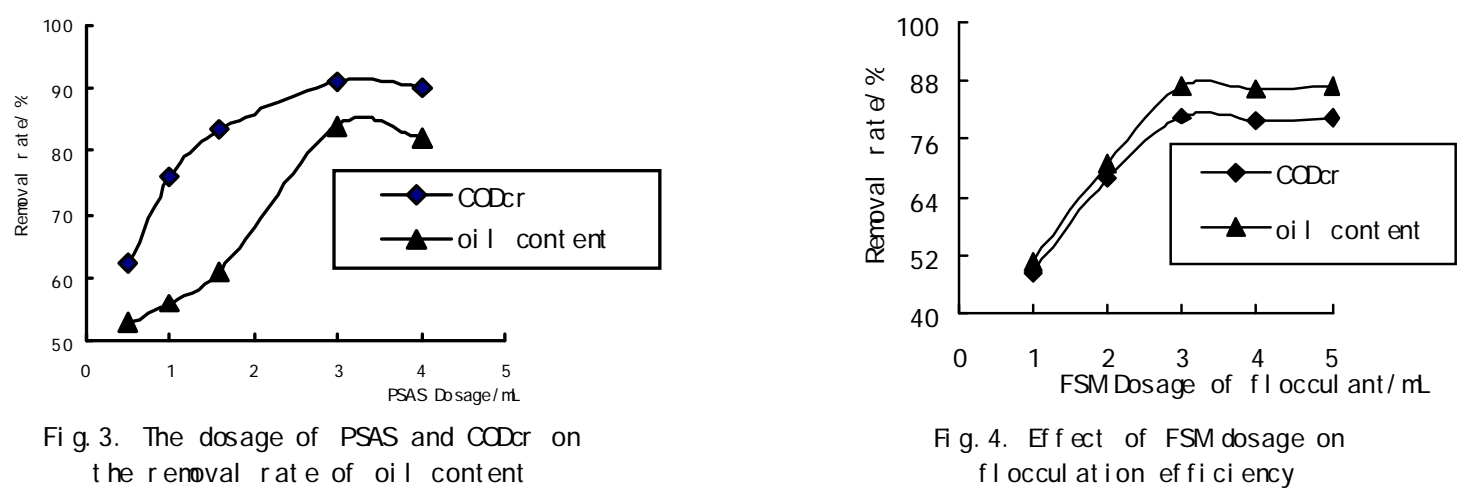

( 3 ) Effect of $\mathrm{pH}$ value of water on PSAS/FSM composite flocculation

In $200 \mathrm{ml}$ oily wastewater samples, PSAS flocculant with $3 \mathrm{~mL}$ and FSM flocculant of $3 \mathrm{~mL}$ were added. Keeping the temperature of raw water unchanged, changing the $\mathrm{pH}$ value of water sample, the influence of $\mathrm{pH}$ value of water sample on the flocculation effect of PSAS/FSM composite flocculant was shown as fig. 5.As shown in Fig. 5, the $\mathrm{pH}$ value of water has little effect on the PSAS/FSM composite flocculation effect. When $\mathrm{pH}$ is 7 , the flocculation effect is best, and the oil content and CODcr removal rate are $94 \%$ and $95 \%$ respectively.

\section{( 4 ) Effect of temperature on flocculation efficiency of PSAS flocculant}

Keep the original conditions unchanged, change the temperature of water samples, get the effect of water temperature on the flocculation effect of PSAS flocculant, such as Fig. 6.

As shown in Fig. 6, with the increase of temperature, the oil content and the removal rate of CODcr are all improved. Increasing the temperature is beneficial to accelerate the hydrolysis speed, and the ability of neutralization and volume sweeping, adsorption and bridging ability. Moreover, the viscosity of oil decreases with the increase of temperature, which is beneficial to the accumulation of oil beads and the improvement of coagulation effect.
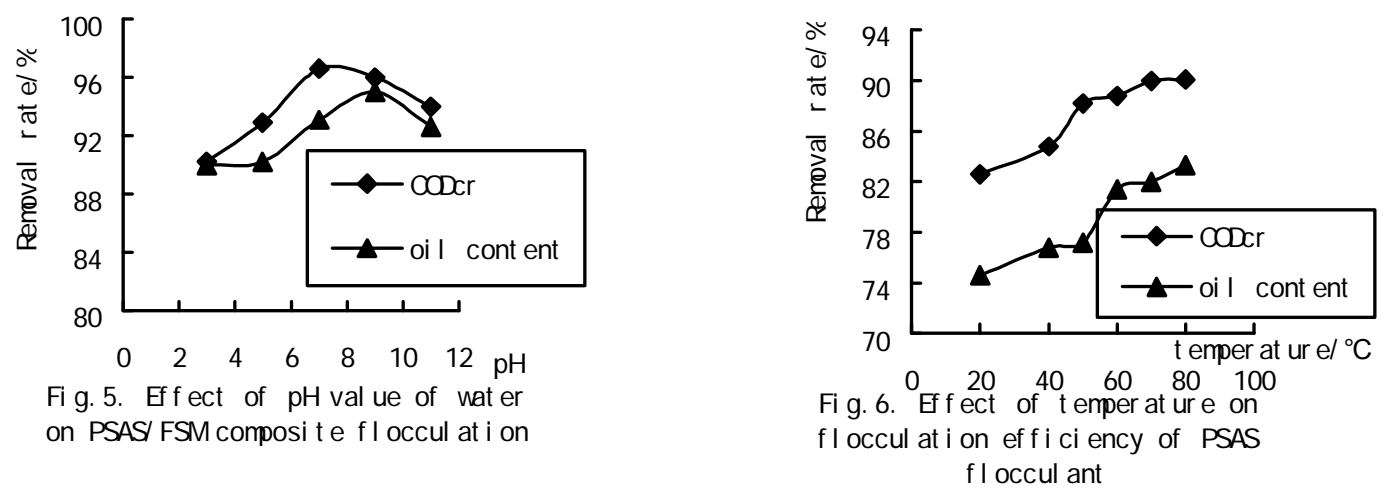

( 5 ) Effect of temperature on flocculation efficiency of FSM flocculant

Keep the original conditions unchanged, use FSM, and investigate the effect of water temperature on FSM effect, such as fig.7. As shown in Fig. 7, the increase of temperature is beneficial to the extension of FSM molecular chain, enhancing the ability of adsorption bridging, sweeping and gathering, and improving the flocculation effect.

( 6 ) Effect of temperature on flocculation efficiency of PSAS/FSM composite flocculant

The influence of water temperature on flocculation efficiency of composite flocculant was obtained, such as fig. 8. According to fig. 8, it can be concluded that with the increase of temperature, the oil content and the removal rate of CODcr are all improved, but the range is not large. Therefore, the influence of temperature on the flocculation efficiency of composite flocculant is less. Considering the relationship between the treatment cost and the treatment effect, the flocculant can be added at the 
original water temperature $\left(60{ }^{\circ} \mathrm{C}\right)$.Moreover, the influence of temperature on the flocculation efficiency of PSAS/FSM composite flocculant is smaller than that of PSAS and FSM.
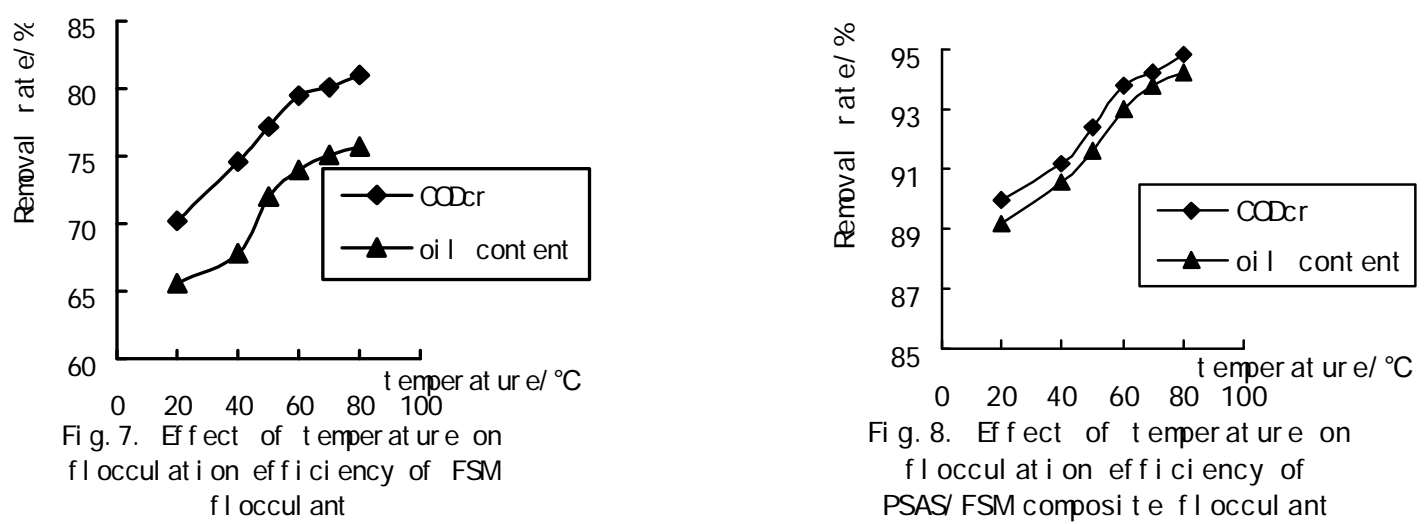

( 7 ) Effect of adding order of PSAS/FSM composite flocculant on flocculation effect

Keep the original conditions unchanged, change the PSAS and FSM dosing sequence. The influence of adding order of PSAS/FSM composite flocculant on flocculation effect was obtained.

Table 3 Effect of adding order of PSAS/FSM composite flocculant on flocculation effect

\begin{tabular}{cccc}
\hline Dosing sequence & $\begin{array}{l}\text { PSAS and FSM are } \\
\text { successively added }\end{array}$ & $\begin{array}{l}\text { Simultaneous addition of } \\
\text { PSAS and FSM }\end{array}$ & $\begin{array}{c}\text { FSM and PSAS are } \\
\text { successively added }\end{array}$ \\
\hline Removal rate of CODcr /\% & 97.90 & 94.21 & 93.40 \\
Oil content removal rate /\% & 93.24 & 90.29 & 90.79 \\
\hline
\end{tabular}

\section{Conclusion}

Starch graft acrylamide polymer flocculants were synthesized in this paper. The influence factors on the graft reaction. The process conditions were optimized. And these studies used with polysilicate aluminum sulfate flocculant, oily wastewater treatment using it. The effects of several factors affecting the flocculation effect, determined the best conditions of use. The experimental results are as follows:

1.The process conditions of graft copolymerization is: the concentration of initiator is $3 \times 10^{-3} \mathrm{~mol} / \mathrm{L}$; the best reaction ratio of starch acrylamide: 1:2; feeding mode reaction in liquid form, multiple dosing; adding initiator after adding acrylamide monomer ;

2. The optimum conditions for the use of PSAS/FSM flocculant are as follows: the optimum dosage of PSAS and FSM is $3 \mathrm{~mL} / 200 \mathrm{~mL}$ oily wastewater; and the flocculation effect is best when the $\mathrm{pH}$ value is about 7; The best use of the temperature of 60 DEG PASA+; FSM flocculation effect is better than that of PASA and FSM mixed dosing after more than FSM+PASA.

3.Compared with other polymer flocculants, the combined use of PSAS and FSM is better than the two alone. Therefore, starch acrylamide modified polymer flocculant FSM is a low cost and high efficiency polymer flocculant, and has great application and promotion value.

\section{References}

[1] Dajun He. Purification and regeneration of industrial waste oil [M].Beijing : Machinery Industry Press , 2001, 10.

[2] An Zhang, Handong Cheng. Environmental protection water injection -- a new way of oilfield wastewater treatment [J]. Safety and environmental engineering , $2003,10(4)$ : 28-30. 
[3] Yun Fang,Yongmei Xia. Bio surfactant [M].Beijing: China Light Industry Press. 1992 , 102-168.

[4] Parkinson M., Bio-surfactants [J]. Biotech.Adv , 1985,3 : 65-83.

[5] Georgiou G . et al., Surface -active Compounds from Microorganisms[J]. Bio . Tech ,1992 , 10 : 60-65.

[6] cairns W. L . et al.., Characterisation of Nocardia Amarae as a Potent Biological Caolescing Agent of Water-oil Emulsion[J] . Appl . Environ. Microbio ., 1982 , 43 : 362-366.

[7] Bana I . M. Biourfactants Prodiction and Possibilel Ues in Microbial Ehanced Oil Recovery and Oil Pollution Remediation [J] . Bioresourse Technology , 1995 , 51:1-12.

[8] Reyes Z,Rist CE,RussellCR.J.Polym.Sci.,PartA-1,1966,4:103-112.

[9]Songhan Pan,Zhen Wang,Guokang Li etc. Effect of starch gelatinization on graft copolymerization of starch and Acrylamide. Fine chemical industry, 1993, 10(4):56-60. 